Published in Matrices, Statistics and Big Data : Selected Contributions from IWMS 2016. Ahmed S., Carvalho F., Puntanen S. (eds). Springer,Cham, 2019. ISBN:978-3-030-17519-1. https://doi.org/10.1007/978-3-030-17519-1_4

\title{
Ingram Olkin (1924-2016): An Appreciation for a People Person
}

\author{
Simo Puntanen \\ School of Information Sciences \\ FI-33014 University of Tampere, Finland \\ email: simo.puntanen@uta.fi
}

George P. H. Styan

Department of Mathematics and Statistics, McGill University, 805 ouest, rue Sherbrooke Street West, Montréal (Québec), Canada H3A 0B9

email: geostyan@gmail.com
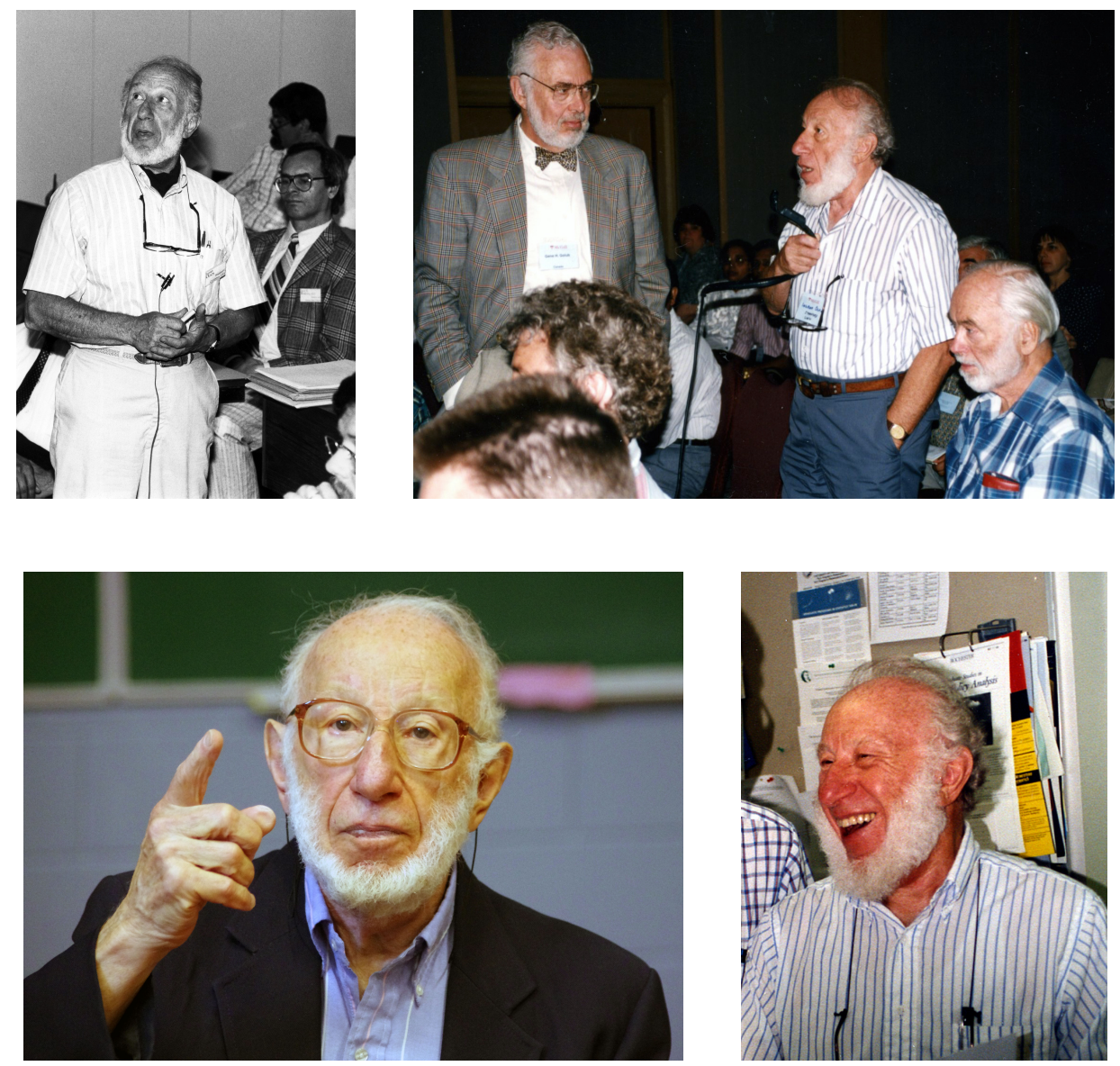
Ingram Olkin, Professor Emeritus of Statistics and Education at Stanford University, Master of multivariate statistical analysis, linear algebra, inequalities, majorization, and meta-analysis, passed away on 28 April 2016 at home in Palo Alto, California, after complications from colon cancer. In the words of his daughter Julia Olkin [7]

"My father, Ingram Olkin, died peacefully on Thursday evening, April 28, 2016, with his daughter Rhoda and wife Anita by his side. He had absolutely no regrets ... both personally and professionally, and led a full, wonderful life. He valued all his friendships with everyone. Thank you for being a part of his life ..."

Richard W. Cottle, Professor Emeritus of Management Science \& Engineering and a close friend of Olkin, said [4]:

"He was a man of remarkable intelligence and affability. His nearly boundless energy was generously used for the welfare of others. It is hard to capture in words the goodness that Ingram showed in his everyday life."

In the conversation part of the Olkin Festschrift [8], Ingram described himself:

"You also know that I'm generally a people person, which is one of the reasons why I've enjoyed students and collaborators. Over the years, the professional contacts have merged with the personal contacts."

We deeply miss you, a truly outstanding and unforgettable People Person, Ingram Olkin.

\section{IWMS}

Now let's go back to some personal memories of Ingram and memorable experiences that we shared with him. One important activity for us was his role in the International Workshop on Matrices and Statistics (IWMS) series [29]. Ingram was a frequent participant at IWMS meetings, and at the IWMS-2004 in Poland we celebrated Ingram's 80th Birthday. On 4 June 2003 his reply to our invitation was this e-mail [Ingram usually used only lower-case letters in his e-mails.]:

"dear all ... wow !!!! how about celebrating my 80th but call it my 60 th .... thanks so much to all of you ... would be pleased to attend."

When Ingram learnt that the IWMS-2014 was to be held in Ljubljana, he immediately, on 22 October 2013, sent this e-mail: 
"... in any case next year is my 90th and what better than to visit ljubljana ... so i do hope to attend. as i see my strength at this point $\mathrm{i}$ should be in good shape by then. so please include me in the program."

It was always great news for the event organizers to have Ingram around: a guarantee of lively colorful sessions, Ingram sitting in the front row and asking questions after each talk. Ingram's role in meetings is nicely described in the Olkin-biography article [9]:

"At most statistics meetings, you will find Ingram in constant conversation - perhaps promoting a new journal, encouraging progress of a key committee, or giving advice about seeking grants or allocating funds. His public accomplishments are many and impressive, but equally important are his behind-the-scenes contributions."

The first IWMS was held in Tampere, Finland, 6-8 August 1990. Ingram gave an invited talk entitled Interface between statistics and linear algebra, which was one of his favorite topics and he practically knew everything about it [22, 24]. For the IWMS-2013 in Toronto he prepared an excellent "linear algebra biography", which was presented there as a poster; see also [25] (2015):

"I gave a brief biography of my introduction to linear algebra and my interaction with some of the linear algebraists at that time."

At the IWMS-1990 in Tampere, Ingram also gave a talk about Gustav Elfving (1908-1984), a famous Finnish statistician, probabilist and mathematician who was a frequent visitor to Stanford. For more about Elfving see Nordström [19, (1999)]. On 19 March 2013 Ingram sent this e-mail to Simo:

"i am cleaning my files and i found folder marked elfving which contains mimeographed notes entitled bayes statistics. it consists of about 40 pages ... so one possibility is that i scan these and send to you ... assuming you want this material ... please advise."

Elja Arjas then found out that these notes were a basis for Elfving's paper [5] published in Skandinavisk Aktuarietidskrift in 1968.

As for Elfving, on 20 May 2011 Ingram wrote the following:

"... my only concern is how to handle the mixture of beer and aquavit. I don't have the right DNA. I once visited gustav elfving and he took me to a meeting of students where they drank beer and aquavit and talked and drank and sang and drank ... i barely made it back to the hotel. So Finland can be a very dangerous country ... but i am willing to take a chance." 
Ingram's performances in Tampere in 1990 can be seen in videos online at YouTube [38]. When we asked for Ingram's permission to show these videos, he replied:

"these are wonderful ... an absolutely great addition to the conference archives. however, you ask for me to give permission to make these public. the answer is in the negative unless you can add some hair and make me look more like james bond. of course, if you do that then i would be glad to grant permission !!!!!"

Kimmo Vehkalahti had agreed to host Ingram and Michael Greenacre in Helsinki, 1-3 July 2011, directly after the IWMS-2011 in Tartu, Estonia. With the kind courtesy of Kimmo, we copy here part of Ingram's travelling protocol.

"dear kimmo: on the basis of my previous experiences in finland I suggest that we just go to a Sauna, drink some beer and listen to michael [Greenacre] sing some of his compositions. ... meanwhile my very best, ingram.

ps. michael ... why don't you write a song with the first three words: sauna, sauna, sauna."

Before coming to Tartu in June 2011, Ingram first went to Vilnius, Lithuania. Just recently, on 27 June 2016, when Simo was leaving for the 10th Tartu Multivariate Conference, he received the following email from Remigijus Leipus:

"Browsing the Tartu conference program I found out that Ingram Olkin is not with us anymore. This was sad news also for Lithuanian mathematicians. In June 2011 Ingram visited Vilnius University where he presented two talks on June 21 and 22. As you know, Ingram's father came from Vilnius, and his mother from Warsaw (later they met there, in Warsaw).

During his stay in Vilnius, with Ingram we were trying to find out information about his father. We visited a Jewish community center and a Jewish cultural center in Vilnius. It was difficult to find any data in such a short time. ... In any case, the time we spent with Ingram in Vilnius was very interesting, I will never forget his energy, sense of humor, attention. ..."

The IWMS-2008 was held in Tomar, Portugal (22-26 July 2008) in celebration of the 90th birthday of T. W. Anderson, mentor of George and grand-mentor of Simo, and a long-time Stanford colleague of Ingram's. We invited Ingram as an after-dinner speaker. On 8 April 2008 he wrote: 
"i replied that i didn't want to give an after-dinner talk. i was going over my files and $\mathrm{i}$ found the after-dinner talk that i gave in 1998 in florida ... so what would you think if $i$ gave the same talk ... maybe with some modest updates. i also kept the photos on transparencies which are different from what simo has."

Unfortunately Ingram was unable to attend the IWMS-2008 in Tomar. On 7 July 2008 he wrote to the IWMS organizers:

" $i$ think that it may make it easier for everyone if $i$ send you the after-dinner speech that $\mathrm{i}$ had in mind. simo is pretty [serious a guy compared with the others $]^{1}$ so he may be a good choice [to present this after-dinner speech]."

Let us borrow a paragraph from Ingram's after-dinner speech:

"I was once interviewed and asked who makes the decisions in our family. I knew the answer in a flash-I make all the big decisions, Anita makes all the small decisions. The only problem is that we haven't had a big decision yet in my 63 years of marriage."

Ingram's title for his (technical) invited talk in Tomar was Moment Inequalities, Mean Inequalities, Matrix Inequalities, and Probability Inequalities: An Inequality Bouillabaisse. Ingram, if anybody, was a Michelin-calibre chef able to cook a delicious Inequality Bouillabaisse!

Section 20.5 in our 2011 Matrix Tricks book [32] deals with How Deviant Can You Be? - the deviation of any particular observation from the mean, building on Ingram's paper [23, (1992)] and Jensen \& Styan [14].

In December 2011 we (Simo \& George) had an interesting and pleasant task: we were to prepare a supporting letter to nominate Ingram Olkin for the Hans Schneider Prize in Linear Algebra. For additional support, we contacted Grace Wahba, Professor of Statistics at the University of WisconsinMadison, and on 31 December 2011 she wrote us:

"I wholeheartedly support the proposal that Ingram Olkin be considered for the Hans Schneider Prize in Linear Algebra. Absolutely he has to get it!"

Though Ingram did not ultimately receive this particular Prize, on 2 August 2012, he kindly sent us a thank-you e-mail:

"simo: thanks for your message and in particular i forgot about the award ... however, i am signing George up to write my obituary (assuming he outlives me !!!!!!!) ... I can always count on him. my best, ingram."

\footnotetext{
${ }^{1}$ wording changed
} 
In the IWMS-2013 in Toronto, Ingram was supposed to be the first speaker on Monday, 12 August. However, on Saturday, 10 August, we received the following email from Ingram:

"dear simo and ejaz: it is now 4 p.m. in california and it is evident that i am not in condition to travel. i don't have a life threatening problem, but i do have a problem ... one of which is that they are not sure what is causing the problem.

i apologize for all the trouble this will cause you. if you do decide to have someone read the talk and i can help, please do let me know.

please convey my regrets to all my friends ... i had looked forward to once again seeing everyone.

my best, ingram"

George presented Ingram's talk in in Toronto.

\section{Inequalities: Theory of Majorization}

In our supporting letter for the Hans Schneider Prize we pointed out that in our view Ingram's most significant contribution in linear algebra was the book Inequalities: Theory of Majorization and Its Applications, with Albert W. Marshall, first published in 1979 [17]. We now have the second edition, with Barry Arnold [18], of the highly-praised classic, without which we know that some people never leave home: now these faithful ones must take into account that the second edition has 909 pages (vs. 569) and its shipping weight is 3.2 pounds (vs. 2.2).

At the end of the first edition of Inequalities: Theory of Majorization and Its Applications [17] there is a section on "Biographies" with a photograph of Issai Schur (1875-1941) on page 525. This was the first photograph of Schur that we found and George used it, with the permission of the "publisher and the authors" of [17], in his article on "Schur complements and linear statistical models" [36. (1983/1985)]; see also [27, 28].

Fuzhen Zhang wrote us on 11 May 2016:

"Dating back to 1984, I went to Beijing Normal University as a graduate student. The first math book in English we used as a text was Ingram's (with Marshall), the 1st edition. I learned and benefited so much from the book. The book has become classical, famous and standard as a reference in this area of research. In 2012, I had the privilege of writing a review for the 2nd edition of the book (published in [39])."

In passing we may mention that Simo wrote of brief review [26] of [18]. 
Ingram had a number of Chinese connections, among them was Kai-Tai Fang. In [16, p. 16 (2015)] he tells the following, which is a nice example of Ingram's organizational generosity!

"During my visit to Stanford University (1981-1982), Professor Ingram Olkin organized a small seminar group on 'multivariate multiple comparisons' which met every week. The participants included T. W. Anderson, Mary Ellen Bock, Zhongguo Cheng and me. ... Then in 1985-1986, upon Professor Ingram Olkin's recommendation, I taught two subjects in the Swiss Federal Institute (ETH, Zürich) as a Guest Professor."

As a further interesting link between Ingram Olkin and Kai-Tai Fang we wish to mention Pao-Lu Hsu, a UK-educated Chinese mathematician, who changed the course of probability and statistics in China. To go back a little, Hsu was employed at the University of North Carolina at Chapel Hill in 1946-1947, then returned to China. In 1948-1951 Ingram was working for his Ph.D. dissertation [35] at Chapel Hill. His supervisors were S. N. Roy and Harold Hotelling, and as Ingram says in the interview part of [8], "Chapel Hill had a galaxy of stars on the faculty". In 33] and 25] Ingram says:

"I had never taken multivariate. I had no idea why I wanted to take multivariate, but I did. I went to Hotelling and I told him that I wanted to take multivariate, and he said, 'Well, why don't you get P. L. Hsu's notes from last year, and study them on your own'... Hsu's proofs were elegant examples of the use of linear algebra in statistics. My thesis in 1951 came out of these lectures."

Interestingly, Pao-Lu Hsu was a supervisor of Kai-Tai Fang in Beijing in the early 1960s. In [16] Kai-Tai Fang tells how Hsu's insistence in fulflling his teaching obligations, despite his weak physical condition, and his dedication to research exerted a great influence on his own future academic career.

George thinks that he first met Ingram at a colloquium in the Department of Mathematical Statistics at Columbia University in the mid-1960s and at that time may well have served Ingram a cup of tea! Ingram then introduced George to "correlation structure", such as when all the correlation coefficients are equal (intraclass correlation) but the variances are not necessarily all equal. This led to George's Ph.D. thesis [35, (1969)]. See also Ingram's paper on "correlations revisited" (with discussion) [21].

George spent the summer of 1970 at Stanford and he believes it was probably there that Ingram introduced him to the seminal paper by Fan \& Hoffman [6, (1955)] in which it is proved that for any $n \times n$ matrix A

$$
\operatorname{ch}_{j}\left(\mathbf{A}+\mathbf{A}^{*}\right) / 2 \leq \operatorname{ch}_{j}^{1 / 2}\left(\mathbf{A} \mathbf{A}^{*}\right), \quad j=1,2, \ldots, n .
$$


Here $\mathrm{ch}_{j}$ denotes the $j$ th largest eigenvalue. See also Marshall \& Olkin [17, p. 240, eq. 4]. The inequalilties (1) were then used by Grossman \& Styan in their article on Theil's BLUS residuals [10, (1972)]. And last, but not least, George is most grateful to Ingram for supporting George's appointment as Editor of The IMS Bulletin, 1987-1992 [37].

\section{$3 \quad$ Fire \& a Good Story}

Here is a descriptive piece of conversation between the interviewer Allan R. Sampson and Ingram Olkin, see [33] (2007):

Sampson: You've been involved with these various forms of applied problems for a long time. But what keeps you still so fired-up?

Olkin: This question about the "fire" is one I have trouble answering.

Sampson: It may precede your beginnings in statistics - perhaps something in your upbringing.

Olkin: I suspect that's true. My mother had fire until she was 98 .

Sampson: Amen!

Olkin: The "fire" was mostly addressed to me. And I think there may be some genetics because my daughters have a certain amount of that transmitted.

Sampson: When you were a child, were you as intense and as passionate in whatever you were doing then as you are now?

Olkin: Let me put it this way ...

In the "Biographies" section (pp. 528-529) of Inequalities: Theory of Majorization and Its Applications [17] there are three photographs of Godfrey Harold Hardy (1877-1947), who with John Edensor Littlewood (1885-1977) and George Pólya (1887-1985) wrote the seminal book Inequalities [11], first published in 1934. G. H. Hardy is featured in The Man Who Knew Infinity [2], a recent British biographical drama film based on the book [15, (1991)] by Robert Kanigel. The film stars Dev Patel as Srinivasa Ramanujan (18871920) and Jeremy Irons as G. H. Hardy. George E. Andrews in his review [1] wrote: "I sincerely hope that every mathematician goes to see this movie", while Allan Hunter [12] in his review of the movie wrote

"It tells such a good story that it is hard to resist".

We agree! Would a movie about Ingram, The Man Who Knew Inequalities: Theory of Majorization, similarly make a good story, hard to resist? 


\section{Acknowledgements}

Warm thanks go to Elja Arjas, Kai-Tai Fang, Michael Greenacre, Harold V. Henderson, Jeffrey J. Hunter, Remigijus Leipus, Peter Šemrl, Evelyn Matheson Styan, Kimmo Vehkalahti, Grace Wahba, and Fuzhen Zhang for their help.

Photographs: Top left $p_{11}$ at IWMS-1990 Tampere (with Jerzy K. Baksalary Yadolah Dodge, photograph courtesy University of Tampere); top right $p_{12}$ at IWMS-1995 Montréal (with Gene H. Golub and T. W. Anderson, photograph by Simo Puntanen); bottom left $p_{21}$ at IWMS-2011 Tartu, Estonia (photograph by Jeffrey J. Hunter); bottom right $p_{22}$ at IWMS-1995 Montréal (photograph by Simo Puntanen).

Shortened versions of this appreciation of Ingram Olkin appeared in [30] and 31 .

\section{References}

[1] George E. Andrews (2016). A Report on the Movie The Man Who Knew Infinity [2]. Notices of the American Mathematical Society, vol. 63, no. 2, pp. 178-180. DOI.

[2] Matt Brown, director \& writer (2015/2016). The Man Who Knew Infinity, movie with Dev Patel as Srinivasa Ramanujan \& Jeremy Irons as G. H. Hardy, trailer online at YouTube.

[3] Dayue Chen and Ingram Olkin (2012). Pao-Lu Hsu (Xu, Bao-lu): The Grandparent of Probability and Statistics in China. Statistical Science, vol. 27 , no. 3 , pp. 434-445. DOI.

[4] Richard W. Cottle \& Julia Olkin (2016). Ingram Olkin, influential Stanford professor of statistics and education, dies at 91. Stanford News (4 May 2016) online at Stanford.

[5] Gustav Elfving (1968). Bayes statistics. Part I-II. Skandinavisk Aktuarietidskrift, vol. 51, pp. 134-144 \& pp. 145-155.

[6] Ky Fan \& Alan Hoffman (1955). Some metric inequalities in the space of matrices. Proceedings of the American Mathematical Society, vol. 6, pp. 111-116.

[7] Nancy Flournoy (2 May 2016). Chief advocate and mentor: Ingram Olkin passes April 28, 2016. CWS: Caucus for Women in Statistics, online at CWS.

[8] Leon Jay Gleser, Michael D. Perlman, S. James Press \& Allan R. Sampson, eds. (1989). Contributions to Probability and Statistics: Essays in Honor of Ingram Olkin. pub. Springer New York. online at SpringerLink. [Published in honor of the sixty-fifth birthday of Professor Ingram Olkin.] 
[9] Leon Jay Gleser, Michael D. Perlman, S. James Press \& Allan R. Sampson $(1989 / 1994)$. A brief biography and appreciation of Ingram Olkin. In Essays in Honor of Ingram Olkin [8, pp. 3-5 (1989)] \& reprinted in Linear Algebra and its Applications. vol. 199, pp. 1-15 (1994): online at ScienceDirect.

[10] Stanley I. Grossman \& George P. H. Styan (1972). Optimality properties of Theil's BLUS residuals. Journal of the American Statistical Association, vol. 67, pp. 672-673, Taylor\&FrancisOnline.

[11] G. H. Hardy, J. E. Littlewood \& G. Pólya (1934). Inequalities. Cambridge University Press.

[12] Allan Hunter (12 September 2015). Review of The Man Who Knew Infinity [2]: online at ScreenDaily.

[13] Jeffrey J. Hunter, ed. (2015). IWMS-2015 Souvenir Booklet of the 24th International Workshop on Matrices and Statistics (25-28 May 2015), pub. Hainan Normal University, Haikou City, Hainan Province, China, 286 pp. full pdf copy online.

[14] Shane T. Jensen \& George P. H. Styan (1999). Some comments and a bibliography on the Laguerre-Samuelson inequality with extensions and applications to statistics and matrix theory. In Analytic and Geometric Inequalities and Applications (Themistocles M. Rassias \& Hari M. Srivastava, eds.), pub. Springer Netherlands, pp. 151-181: online at Springer.

[15] Robert Kanigel (1991/2016). The Man Who Knew Infinity: A Life of the Genius, Ramanujan. C. Scribner's, New York. "Movie tie-in edition" (26 April 2016): Robert Kanigel website. Hardcover \& Kindle editions: amazon.com

[16] Agnes W. L. Loie, Lucinda Li, Simo Puntanen \& George P. H. Styan (2015). A conversation with Kai-Tai Fang. In the IWMS-2015 Souvenir Booklet [13, pp. 1-39].

[17] Albert W. Marshall \& Ingram Olkin (1979). Inequalities: Theory of Majorization and Its Applications, pub. Academic Press, New York.

[18] Albert W. Marshall, Ingram Olkin \& Barry C. Arnold (2011). Inequalities: Theory of Majorization and Its Applications, 2nd edition, pub. Springer New York: online at SpringerLink.

[19] Kenneth Nordström (1999). The life and work of Gustav Elfving, Statistical Science, vol. 14, no. 2, pp. 174-196. DOI.

[20] Ingram Olkin (1951). On Distribution Problems in Multivariate Analysis, $\mathrm{PhD}$ dissertation in Statistics, University of North Carolina, Chapel Hill (Harold Hotelling \& S. N. Roy, Advisors), Institute of Statistics. Mimeograph series no. 43, 126 pp. 
[21] Ingram Olkin (1967). Correlations revisited (with discussion). Chapter 3 in Improving Experimental Design and Statistical Analysis: Seventh Annual Phi Delta Kappa Symposium on Educational Research (Julian C. Stanley, ed.), pub. Rand McNally, Chicago, pp. 102-156, 292-301.

[22] Ingram Olkin (1990). Interface between statistics and linear algebra. In Matrix Theory and Applications (Charles R. Johnson, ed.), Proceedings of Symposia in Applied Mathematics, vol. 40, pub. American Mathematical Society, Providence, Rhode Island, pp. 233-256: "Lecture notes prepared for the American Mathematical Society Short Course [on] Matrix Theory and Applications, held in Phoenix, Arizona, January 10-11, 1989". Preprint online at Stanford, $35 \mathrm{pp}$.

[23] Ingram Olkin (1992). A matrix formulation on how deviant an observation can be. The American Statistician, vol. 46, no. 3, pp. 205-209: online at JSTOR.

[24] Ingram Olkin (1998). Why is matrix analysis part of the statistics curriculum? Student: A Statistical Journal for Graduate Students, vol. 2, no. 4 , pp. $434-348$.

[25] Ingram Olkin (2015). A linear algebra biography. Linear Algebra and its Applications. vol. 473, pp. 3-13: online at ScienceDirect.

[26] Simo Puntanen (2011). Book review of Inequalities: Theory of Majorization and Its Applications, 2nd edition [18]. International Statistical Review, vol. 79, no. 2, p. 293. DOI.

[27] Simo Puntanen \& George P. H. Styan (2004). Historical introduction: Issai Schur and the early development of the Schur complement. Chapter 0 and Bibliography in The Schur Complement and Its Applications (Fuzhen Zhang, ed.), pub. Springer Science+Business Media, pp. 1-16, 259-288: online at SpringerLink.

[28] Simo Puntanen \& George P. H. Styan (2006). Some comments about Issai Schur (1875-1941) and the early history of Schur complements. In Contributions to Probability and Statistics: Applications and Challenges - Proceedings of the International Statistics Workshop, University of Canberra, 4-5 April 2005 (Peter Brown, Shuangzhe Liu \& Dharmendra Sharma, eds.), World Scientific, Singapore, pp. 28-66: online at WorldScientific.

[29] Simo Puntanen \& George P. H. Styan (2015). Twenty-six years of the International Workshop on Matrices and Statistics (IWMS): 1990-2015. In the IWMS-2015 Souvenir Booklet [13], pp. 40-58.

[30] Simo Puntanen \& George P. H. Styan (2016a). Ingram Olkin (19242016): Some personal memories. Book of Abstracts of the 25th IWMS, 
Funchal, Madeira, 6-9 June 2016. Daniel Klein \& Francisco Carvalho, eds., Institute Nacional de Estatística, Portugal, pp. 121-129. Download. IWMS-2016 home page.

[31] Simo Puntanen \& George P. H. Styan (2016b). Obituary. Ingram Olkin (1924-2016): Some personal memories. Image: The Bulletin of the International Linear Algebra Society, no. 56, pp. 22-26. Download. [Shortened version of [30].]

[32] Simo Puntanen, George P. H. Styan \& Jarkko Isotalo (2011). Matrix Tricks for Linear Statistical Models: Our Personal Top Twenty, pub. Springer Berlin Heidelberg: online at SpringerLink.

[33] Allan R. Sampson (2007). A conversation with Ingram Olkin. Statistical Science, vol. 22, no. 3, pp. 450-475. DOI. [Some sources refer to this article as "Ingram Olkin \& Allan R. Sampson (2007)" rather than "Allan R. Sampson (2007)". ]

[34] Paul Samuelson (1968). How deviant can you be? Journal of the American Statistical Association, vol. 63, no. 324, pp. 1522-1525: online at JSTOR.

[35] George P. H. Styan (1969). Multivariate Normal Inference with Correlation Structure, $\mathrm{PhD}$ dissertation in Mathematical Statistics, Columbia University, New York City (T. W. Anderson, Advisor), v + 199 pp.

[36] George P. H. Styan (1985). Schur complements and linear statistical models. In Proceedings of the First International Tampere Seminar on Linear Statistical Models and their Applications: Tampere, Finland, August-September 1983 (Tarmo Pukkila \& Simo Puntanen, eds.), Dept. of Mathematical Sciences, University of Tampere, pp. 37-75.

[37] George P. H. Styan (1992). Six-Year Index to Obituaries, PhDs in the Statistical Sciences [and] Photographs [in The IMS Bulletin, vol. 16-21 (1987-1992)]. The IMS Bulletin, vol. 21, pp. 650-653.

[38] University of Tampere (2015). Conferences in Statistics: 70 videos from conferences at the University of Tampere in 1987 and 1990: videos online at YouTube.

[39] Fuzhen Zhang (2012). Book review of Inequalities: Theory of Majorization and Its Applications, 2nd edition [18. Linear Algebra and its Applications, vol. 436, pp. 1535-1540: online at ScienceDirect. 